\title{
Reduction of Zygomatic Fractures Using the Carroll-Girard T-bar Screw
}

\author{
Ji Eun Baek, Chan Min Chung, In Pyo Hong \\ Department of Plastic and Reconstructive Surgery, National Medical Center, Seoul, Korea
}

Zygomatic fractures are the second most common facial bone fractures encountered and treated by plastic surgeons. Stable fixation of fractured fragments after adequate exposure is critical for ensuring three-dimensional anatomic reduction. Between January 2008 and December 2010, 17 patients with zygomatic fractures were admitted to our hospital; there were 15 male and 2 female patients. The average age of the patients was 41 years (range, 19 to 75 years). We exposed the inferior orbital rim and zygomatic complex through a lateral brow, intraoral, and subciliary incisions, which allowed for visualization of the bone, and then the fractured parts were corrected using the Carroll-Girard T-bar screw. Postoperative complications such as malar asymmetry, diplopia, enophthalmos, and postoperative infection were not observed. Lower eyelid retraction and temporary ectropion occurred in 1 of the 17 patients. Functional and cosmetic results were excellent in nearly all of the cases. In this report, we describe using the Carroll-Girard T-bar screw for the reduction of zygomatic fractures. Because this instrument is easy to use and can rotate to any direction and vector, it can be used to correct displaced zygomatic bone more accurately and safely than other devices, without leaving facial scars.

Keywords Zygomatic fracture / Reconstructive surgical procedures/ Equipment and supplies

\author{
Correspondence: In Pyo Hong \\ Department of Plastic and \\ Reconstructive Surgery, National \\ Medical Center, 245 Eulji-ro, Jung-gu, \\ Seoul 100-799, Korea \\ Tel: $+82-2-2260-7207$ \\ Fax: +82-2-2263-8531 \\ E-mail:nmcps@unitel.co.kr
}

This article was presented as a poster at the 67th Congress of the Korean Society of Plastic and Reconstructive Surgeons on November 19-22, 2009 in Seoul, Korea.

No potential conflict of interest relevant to this article was reported.

Received: 11 Jun 2012 • Revised: 2 Aug 2012 • Accepted: 6 Aug 2012

pISSN: 2234-6163 • elSSN: 2234-6171 • http://dx.doi.org/10.5999/aps.2012.39.5.556• Arch Plast Surg 2012;39:556-560

\section{INTRODUCTION}

Zygomatic fractures are the second most common facial fractures encountered and treated by plastic surgeons, although the appropriate treatment modalities remain a topic of considerable debate [1]. The common goal of all treatments is an exact three-dimensional (3-D) restoration of the disturbed anatomy [2]. Surgical exposure of zygomatic fractures has been achieved through a variety of approaches including the intraoral (Keen), temporal (Gillies), and brow and lower eyelid subciliary incisions. Reduction and fixation has been performed using bone clamps, towel clips, hemostats, clamps, and a variety of elevators. We have found that the Carroll-Girard T-bar screw is an effective treatment modality. This T-shaped instrument has a broad horizontal handle that allows for easy manipulation of the instrument and for the rotation of the zygoma in all directions [3]. Because the T-bar screw is firmly attached to the zygomatic bone, and the screw is grasped as a handle, total control of the displaced bone is possible. In this article, we describe the exclusive use of the Carroll-Girard T-bar screw for the reduction and fixation of zygomatic fractures.

\section{IDEA}

From January 2008 to December 2010, we retrospectively reviewed 17 patients (15 male, 2 female) with zygomatic frac- 
tures caused by slip-and-fall injuries ( 4 cases), assaults or fights ( 4 cases), traffic accidents ( 4 cases), motorcycle accidents ( 4 cases), and an industrial accident ( 1 case). The average age was 41 years (range, 19 to 75 years). Although a variety of schemes can be used to classify zygomatic fractures, we used the Knight and North Classification System (Table 1) and chose group III, $\mathrm{IV}$, and $\mathrm{V}$ fractures, because their repair requires open reduction and stabilization (Table 2) with adequate osteosynthesis [4]. The 3-D reduction and restoration of facial contours requires adequate exposure of fracture sites. We achieved this via lateral brow, intraoral, and subciliary incisions. In all of the cases, an intraoral incision was first performed to dissect the nasomaxillary and zygomaticomaxillary buttresses, and a blunt elevator was next inserted beneath the zygomatic arch, and intraoral reduction was then attempted. Before lower eyelid incision, a forced duction test for ocular motility was conducted to determine the presence or absence of extraocular muscle entrapment. After injection of $1 \%$ lidocaine with epinephrine in a 1:100,000 solution, a cutaneous incision was made in a skin crease several millimeters below the eyelash line. The stepped skin-muscle

\section{Fig. 1. The use of the Carroll-Girard T-bar}

The T-shaped instrument allows easy manipulation and rotation of the zygoma in all directions. The Carroll-Girard T-bar was placed in the lateral aspect of the malar eminence.

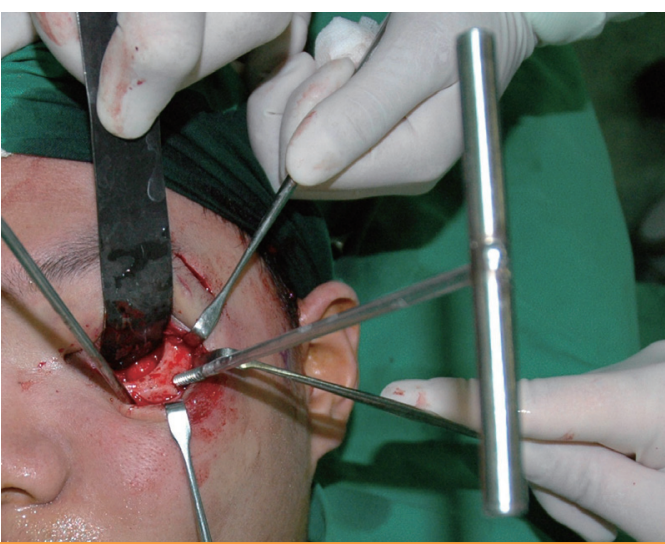

\section{Table 1. Knight and North Classification System}

\section{Type of fracture}

Group I

Group II

Group III

Group IV

Group V

Group VI

\section{Fracture patterns}

No significant displacement; fractures visible on radiograph, but fragments remain in line $(6 \%)$ Arch fractures, which involve inward buckling of the arch with no orbital or anterior involvement (10\%) Unrotated body fractures; downward and inward displacement, but no rotation (33\%)

Medially rotated body fractures; downward, inward, and backward displacement with medial rotation (11\%) Laterally rotated body fractures; downward, backward, and medial displacement with lateral rotation of the zygoma (22\%) All case in which additional fracture lines cross the main fragment (18\%)

From Knight and North. [4], with permission from Elsevier.

\section{Table 2. Summary of the clinical features and outcomes}

\begin{tabular}{|c|c|c|c|c|c|c|}
\hline Case & $\begin{array}{l}\text { Age }(y r) / \\
\text { Sex }\end{array}$ & Cause of injury & $\begin{array}{l}\text { Knight and North } \\
\text { Classification } \\
\text { System }\end{array}$ & Associated injury & Follow-up (mo) & $\begin{array}{l}\text { Postoperative } \\
\text { complications }\end{array}$ \\
\hline 1 & $47 / M$ & Traffic accident & Group IV & - & 6 & \\
\hline 2 & $19 / \mathrm{M}$ & Motor cycle accident & Group V & - & 12 & \\
\hline 3 & $51 / M$ & Slip and fall & Group III & Blow-out fracture, Rt. & 6 & \\
\hline 4 & $28 / M$ & Fighting & Group III & Blow-out fracture, Rt. & 12 & Numbness of cheek \\
\hline 5 & $46 / M$ & Traffic accident & Group III & - & 18 & \\
\hline 6 & $25 / M$ & Motor cycle accident & Group IV & Blow-out fracture, Rt. & 18 & \\
\hline 7 & 73/M & Slip and fall & Group III & Blow-out fracture, Rt. & 18 & Temporary ectropion \\
\hline 8 & $50 / \mathrm{M}$ & Traffic accident & Group IV & - & 24 & Numbness of cheek \\
\hline 9 & $37 / \mathrm{M}$ & Fighting & Group IV & Blow-out fracture, Rt. & 12 & \\
\hline 10 & $36 / \mathrm{M}$ & Fighting & Group V & - & 12 & \\
\hline 11 & $25 / M$ & Motor cycle accident & Group V & - & 12 & \\
\hline 12 & $42 / M$ & Industrial accident & Group IV & - & 6 & Numbness of cheek \\
\hline 13 & $25 / M$ & Motor cycle accident & Group V & $\begin{array}{l}\text { Mandibular fracture, Lt. } \\
\text { (body) }\end{array}$ & 18 & \\
\hline 14 & $71 / F$ & Slip and fall & Group V & - & 6 & \\
\hline 15 & 28/M & Fighting & Group IV & Blow-out fracture, Rt. & 6 & \\
\hline 16 & $25 / F$ & Traffic accident & Group IV & Blow-out fracture, Rt. & 6 & \\
\hline 17 & $75 / M$ & Slip and fall & Group V & - & 12 & Numbness of cheek \\
\hline
\end{tabular}




\section{Fig. 2. Case 1}

(A) Exposure of the inferior orbital rim through a subciliary incision. Another incision was performed on the right lateral eyebrow revealing a blow-out fracture on the right orbital floor. (B) Fixation of the inferior orbital rim using a curved 6-hole absorbable plate and biodegradable screws. Herniated orbital soft tissue was restored and a piece of absorbable mesh plate was placed on the orbital floor and fixed with screws. (C) Preoperative axial view of computed tomographic (CT) scans showing a displaced zygomatic complex. (D) Postoperative axial view of CT scans showing the zygomatic complex, which was anatomically reconstructed using an absorbable plate. (E) Preoperative three-dimensional (3-D) CT reconstruction showing a zygomatic fracture. (F) Postoperative 3-D CT reconstruction showing an absorbable plate and biodegradable screws.
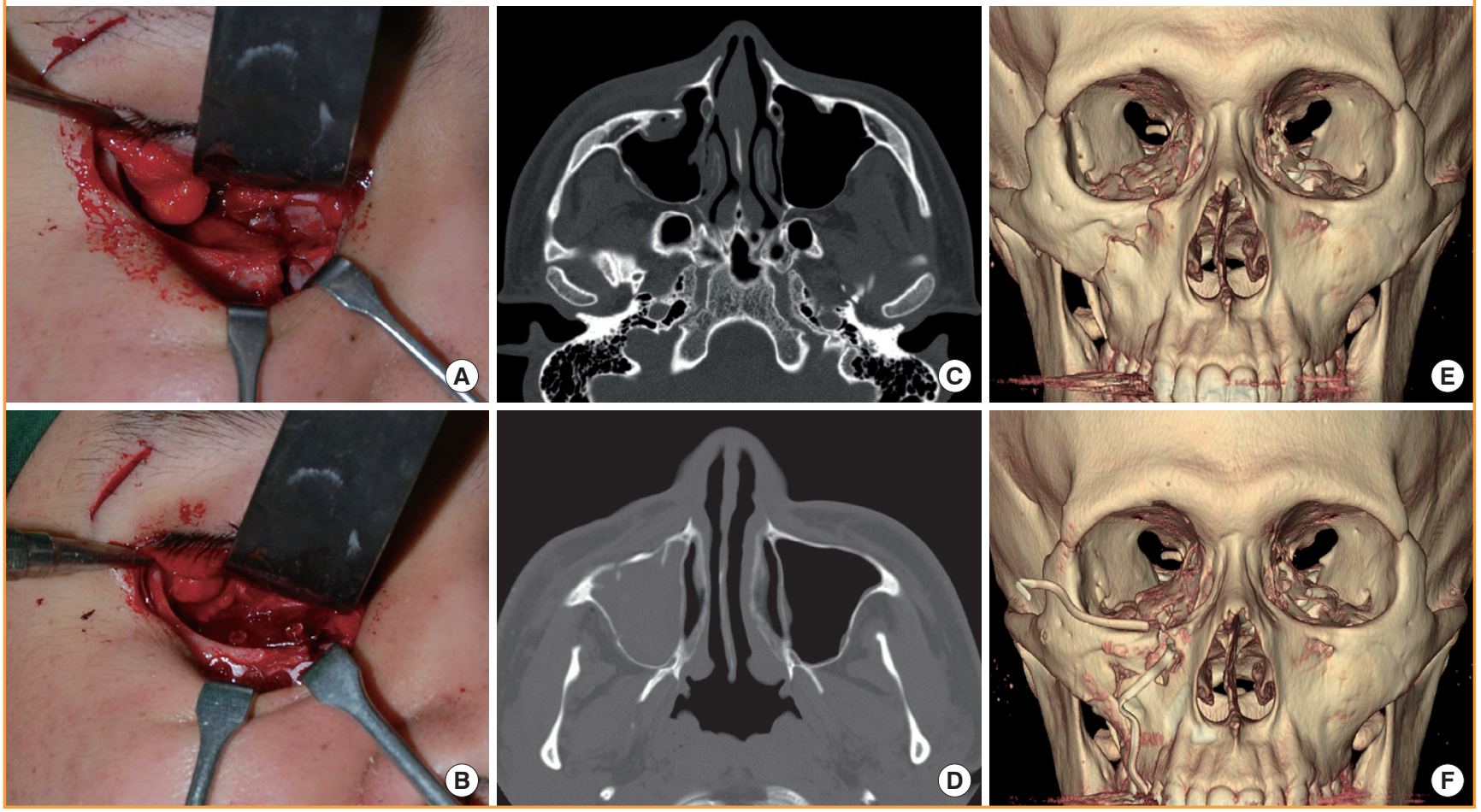

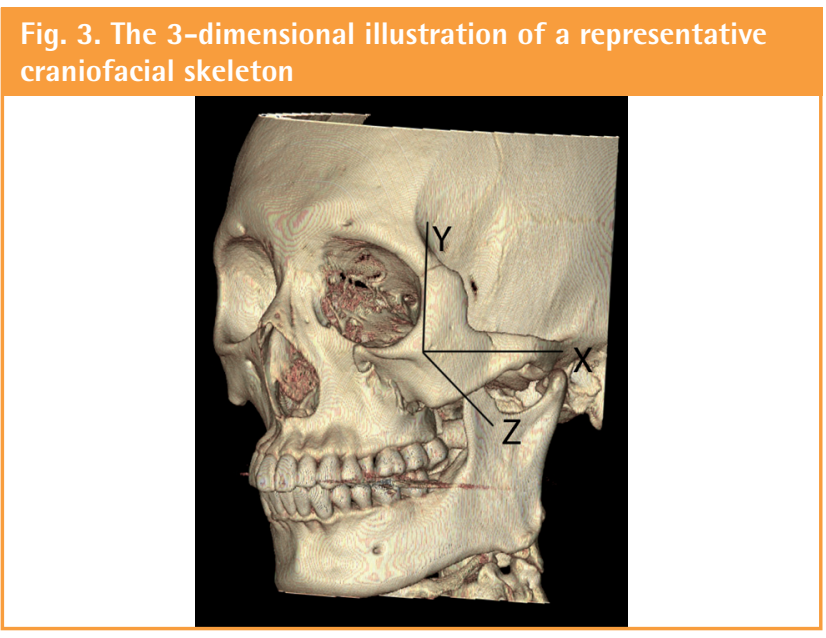

approach divides the orbicularis muscle approximately $2-3 \mathrm{~mm}$ below the level of the skin incision, follows a preseptal plane to the orbital rim, and then continues through the periosteum to the orbital floor. Although denervation of the orbicularis oculi muscle, vertical shortening, and ectropion occur more frequently using this approach, it is technically easier and produces more favorable aesthetic results [5]. Using a blade, the periosteum is incised $2 \mathrm{~mm}$ anterior to the orbital rim, and subperiosteal elevation is performed to expose the fracture sites. After the malar eminence is exposed, the bone is penetrated into the maxillary sinus using a perforating drill. The Carroll-Girard T-bar screw is introduced into the drilled opening and rotated in a clockwise direction until it is firmly placed within the bone, usually at a depth of 10 to $20 \mathrm{~mm}$ (Fig. 2). The horizontal bar on the screw is used for grasping and manipulating the screw as needed, and to also provide control of the attached zygomatic bone using multidirectional rotary force (Fig. 3). When direct visualization of fractured sites is achieved, the zygoma is manipulated in the required direction to set the bone into its anatomic position. For a medially rotated zygomatic fracture, the zygomatic complex is manipulated by pulling it in the opposite direction to pivot around the z-axis, and then the entire complex is rotated in a clockwise direction around the y-axis. For laterally rotated zygomatic fractures, the zygomatic complex is pivoted around the z-axis, and then the entire complex is rotated in the opposite direction by pivoting it in a counter-clockwise direction around the y-axis. The zygomatic complex is then held in position with the Carroll-Girard T-bar screw as the infraorbital rim is plated 
with a 6-hole curved absorbable plate, and the frontozygomatic suture line is fixed using a 4-hole straight absorbable plate. Finally, an L-shaped absorbable plate is placed laterally along the zygomaticomaxillary buttress. Strict attention must be given to layered closure, which includes resuspension of the soft tissue. The periosteum is closed over all of the fixation plates using 5-0 polyglactin sutures, and the skin is closed using 6-0 nylon sutures. The patients remained in the hospital for 7 days and were visually monitored for disturbances to their repairs, and then they were discharged with oral antibiotics. Postoperatively, all of the patients were assessed at regular intervals to check for postoperative complications including malar asymmetry, diplopia, enophthalmos, and cheek anesthesia. All procedures were evaluated by the surgeon, and all of the patients were considered to have had symmetrical repairs, in which the malar eminence was restored. There were no instances of malar asymmetry, diplopia, enophthalmos, or postoperative infection. Four of the 17 patients complained of an intermittent decrease in infraorbital sensation or numbness of the cheek overlying the fractured site; sensation usually improved after 3 months. One of the 17 patients experienced lower eyelid retraction and temporary ectropion, but the functional and cosmetic results were excellent in the other 16 cases.

\section{DISCUSSION}

The zygomatic and maxillary bones provide contour and symmetry to the face. Due to their morphologic prominence, they are the second most commonly fractured sites after the nasal bone [1]. The fractured zygomatic bone is usually dislocated in an inferomedial and posterior direction, resulting in a cosmetic deformity with loss of the ipsilateral malar eminence, possible depression of the zygomatic arch, asymmetry of the bony orbital circumstance, and possible enophthalmos [2,3]. For the most accurate reduction of a zygomatic fracture, the zygomaticofrontal articulation, infraorbital rim, and zygomaticomaxillary buttress should be exposed and properly aligned. Once alignment of these articulations has been achieved, accurate reduction of the fracture to its anatomical location can be performed [6]. Building on Karlan's concept of the zygoma as a pyramid, we have imagined the zygomatic complex as a 3-D shape with three axes intersecting at the malar eminence (Fig. 3). The $\mathrm{x}$-axis (horizontal axis) is represented by a line through the inferior orbital rim and extending horizontally onto the surface of the zygomatic arch. The y-axis (vertical axis) is represented by a vertical line extending from the frontozygomatic suture line inferiorly along the lateral wall of the orbit. The z-axis is represented by a line drawn perpendicular to the malar eminence and parallel to the lateral wall of the orbit $[1,7]$. An ideal reduction using this analysis applies both linear and rotary forces in the opposite direction of the original injury. For example, medially rotated body fractures (group IV, Knight and North Classification) appear to be caused by a blow to the malar eminence from above the horizontal axis of the bone [4]. This also drives the bone backwards, inwards, and downwards, and for a right malar fracture, with a clockwise rotation. For reduction, we pull the zygomatic complex around the $\mathrm{z}$-axis and then rotate the entire complex in the opposite direction by pivoting it around the $y$ axis. The most important aspect of the treatment of zygomatic complex fractures is careful exposure of all the fractures and their accurate reduction in a 3-D fashion [8]. Facial symmetry is achieved by restoring the 3-D position of the malar prominence, and orbital volume is restored by the zygomaticosphenoid alignment at the lateral orbital wall. Many methods and objects have been used to set the zygomatic [9] fractures into an anatomic position such as towel clips, hemostats and clamps, bone hooks, and a variety of elevators [3]. With most techniques, reduction is difficult, inaccurate, and impossible to maintain because orbital fractures involving some or all of the zygomatic articulations (zygomaticosphenoid, zygomaticofrontal, zygomaticomaxillary, and zygomaticotemporal) are commonly encountered $[4,8]$. In our experience, the application of bone elevators or towel clips is limited by the ability of the surgeon to titrate force along all three dimensions. The use of the Carroll-Girard T-bar fixation screw solves such problems by allowing the precise manipulation and anatomic reduction of zygomatic fractures. The T-bar screw is easy to use and rotatable to any direction [7]. Despite these benefits, many surgeons are unwilling to use the device because they are accustomed to using percutaneous stab incisions to expose protruding parts of zygomatic bones. In our patients, fractured bone was exposed through a lateral brow, intraoral, and subciliary incision, which allowed us to visualize the fractures and then correct them using the T-bar screw. Because this method allowed us to quickly exert concentrated force directly to the fractured parts, compound zygomatic fractures were more accurately and safely corrected in all of our patients, without leaving facial scars.

\section{REFERENCES}

1. Meslemani D, Kellman RM. Zygomaticomaxillary complex fractures. Arch Facial Plast Surg 2012;14:62-6.

2. Kelley P, Hopper R, Gruss J. Evaluation and treatment of zygomatic fractures. Plast Reconstr Surg 2007;120:5S-15S.

3. Kreutziger KL. Zygomatic fractures: reduction with the Tbar screw. South Med J 1992;85:1193-202. 
4. Knight JS, North JF. The classification of malar fractures: an analysis of displacement as a guide to treatment. Br J Plast Surg 1961;13:325-39.

5. Rohrich RJ, Janis JE, Adams WP Jr. Subciliary versus subtarsal approaches to orbitozygomatic fractures. Plast Reconstr Surg 2003;111:1708-14.

6. Hollier LH, Thornton J, Pazmino P, et al. The management of orbitozygomatic fractures. Plast Reconstr Surg 2003;111: 2386-92.
7. Chang EL, Hatton MP, Bernardino CR, et al. Simplified repair of zygomatic fractures through a transconjunctival approach. Ophthalmology 2005;112:1302-9.

8. Karlan MS, Cassisi NJ. Fractures of the zygoma. A geometric, biomechanical, and surgical analysis. Arch Otolaryngol 1979;105:320-7.

9. Kaufman Y, Stal D, Cole P, et al. Orbitozygomatic fracture management. Plast Reconstr Surg 2008;121:1370-4. 